\title{
Nature's wrath or human casualness! Whose fault is it anyway?
}

Sir,

Roadside accidents have increased tremendously in the last decade resulting in increased morbidity and mortality both in the developing and developed nations. ${ }^{[1]}$ However, there can be instances where accident happens on the road without any vehicular involvement. The present communication intends to convey one very important incident which throws numerous questions to the administrators, general public, and traffic policy makers.

A 42-year-old Sikh male was driving on a two-wheeler in one of the cities of northern India when he suddenly met with an unusual accident. While driving, he started yawning and suddenly he felt something going into his mouth. He hardly had time to react to this strange intrusion when he suddenly felt a stinging sensation in his throat. He stopped his vehicle and tried to find out the cause of the pain in the throat. He felt something moving in his pharyngeal area and asked a passerby to have a look into his throat. Nothing could be seen in the neck region. He started feeling the development of a lump in his throat which was felt to be gradually increasing in the size. An ambulance was called from public helpline number which arrived in 15 minutes. By that time the patient had started developing breathing difficulty and cyanosis.

He was taken to the nearby hospital and on the way his condition deteriorated as he started developing progressive dyspnoea. He developed apnea and cardio-respiratory arrest in the ambulance only. Efforts were made to secure the airway but were not successful as there was massive swelling in throat and nothing could be visualized with laryngoscope. However, cardio-pulmonary resuscitation was initiated with ambu bag and chest compressions.

On reaching the health center, he was immediately shifted to adjoining emergency ward, intravenous line was secured and attempts were made to secure airway through intubation. Failure to intubate was followed by emergency tracheostomy and insertion of tracheostomy tube no $7.5 \mathrm{~mm}$ ID. Meanwhile, cardiopulmonary resuscitation (CPR) was continued.

During these maneuvers, patient's pulse was not palpable and blood pressure could not be recorded. Physical and pharmacological resuscitation could not revive the patient; therefore, direct current electric shock was delivered to the patient as per protocols. In spite of all resuscitative efforts patient could not be revived and was declared dead after 45 minutes of resuscitative procedure. Patient's relatives were called and the dead body was handed over to them after post-mortem examination.
Such incidents are rare and have hardly been mentioned in the literature. Whether such issues are of public health concern, resource limitedness, human casualness or a natural disaster, it is a difficult answer to explore. The biting of an insect in the throat during roadside journey can be attributed to a natural accident with catastrophic consequences. However, insect or wasp bite can lead to swelling and airway obstruction, anaphylaxis and can also lead to multiple organ failure. ${ }^{[2-4]}$

The yawning is a natural physiological phenomenon and it is difficult to stop it voluntarily during driving. Wearing of helmet with face covering was not possible in this situation as the rider was a Sikh gentleman and it is not possible to wear helmet on the turban. Moreover, wearing of helmet or face cover is somewhat against religious ethics too. So it is not fair to term the accident as human casualness.

The ambulances are not well-equipped with advanced equipment, leave aside the availability of doctors for 24 hours in a resourcechallenged nation of ours. The availability of these resources could have helped in securing the invasive airway in the ambulance only and could have possibly saved the life of the victim. The bite of any insect on the soft tissue can lead to a rapid massive swelling and can be fatal if this can occur in the vital areas such as throat.

Airway instrumentation requires a special training in these difficult situation or the services of an anesthesiologist, ENT specialist, or emergency physician which was not possible in the present scenario. As such, the resource-challenged settings of our nation can also not to be blamed for this mortality.

This incidence can be termed as a natural causality along with bad luck of the patient which led to an avoidable mortality. How such mishaps can be prevented in a resource-challenged nation is of a serious concern. The responsibility of such accidents has to be shared by public health administrators, health administrators, and the general public.

\section{Sukhminder Jit Singh Bajwa}

Department of Anaesthesiology and Intensive Care Medicine, Gian Sagar Medical College and Hospital, Ram Nagar, Rajpura, Patiala, Punjab, India.

Address for the Correspondence: House No-27-A, Ratan Nagar, Tripuri, Patiala, Punjab, India E-mail: sukhminder_bajwa2001@yahoo.com 


\section{REFERENCES}

1. Bajwa SS, Kaur J, Bajwa SK, Kaur G, Singh A, Parmar SS, et al. Designing, managing and improving the operative and intensive care in polytrauma. J Emerg Trauma Shock 2011;4:494-500.

2. Sharmila RR, Chetan $G$, Narayanan P, Srinivasan S. Multiple organ dysfunction syndrome following single wasp sting. Indian J Pediatr 2007;74:1111-2.

3. Atmaram VP, Mathew A, Kurian G, Unni VN. Acute renal failure following multiple wasp stings. Indian J Nephrol 2005;15:30-2.

4. Yates AB, Moffitt JE, Shazo R. Anaphylaxis to arthropod bites and stings Consensus and Controversies. Immunol Allergy Clin North Am 2001;21:1-13.

\begin{tabular}{|l|l|}
\hline Access this article online & Website: \\
\hline Quick Response Code: & www.ijmedph.org \\
\cline { 2 - 3 } & DOl: \\
\hline & 10.4103/2230-8598.123532 \\
\cline { 1 - 2 } & \\
\hline
\end{tabular}

